\title{
A Conquista da Segurança
}

\author{
The Conquest of Security
}

La Conquista de la Seguridad

Celso Marcos da Silva ${ }^{1}$

O livro dos autores organizadores Paulo Sousa e Walter Mendes1 fala sobre a segurança do paciente nos diversos níveis de assistência. Composto por 2 partes, onde a primeira contem 6 capítulos e a segunda 10, apresenta entre seus autores, profissionais brasileiros e portugueses, de diversas áreas da saúde, entre elas: medicina, enfermagem, gestão, advocacia, nutrição, psicologia farmácia, engenharia elétrica. Uma diversidade de autores que demonstra a complexidade e importância do tema abordado.

A primeira parte do livro versa sobre a qualidade em saúde e segurança do paciente em seus aspectos fundamentais e seus capítulos são divididos em vários contextos entre eles: a qualidade do cuidado em saúde, (abordando o alto custo da saúde), a incorporação tecnológica, a necessidade de trabalhar com evidência científica. Descreve os atributos necessários para uma qualidade no cuidado e apresenta a tríade da qualidade: estrutura, processo e resultado fazendo intersecção entre qualidade do cuidado e segurança do paciente. Aborda ainda a história e desenvolvimento da segurança do paciente em uma viagem pela arte do cuidar que vai desde o Egito antigo ( 500 a.C.), passando por Hipócrates, Galeno, e muitos outros como John Wennberg e Archie Cochrane.

Descreve o relatório To Err is

${ }^{1}$ Médico. Especialista em Medina da Família. Mestrando do Prof. Saúde pela FIOCRUZ. Autor correspondente: Av. Manoel Severino Barbosa. S/N. Bom Sucesso. CEP: 57309-005. Arapiraca, Alagoas, Brasil.

Recebido: Nov/2017 - Aceito: Dez/2017. 
Human que provocou interesse pelo tema segurança do paciente, dando início a formulação de estudos e políticas para promoção de práticas do cuidado, estabelecendo segurança e qualidade para os pacientes e profissionais. Os capítulos falam ainda de taxonomia em segurança do paciente, erro e violações no cuidado em saúde, mostrando a importância dos aspectos epidemiológicos dos eventos adversos na perspectiva de criar estratégias para diminuir suas incidências, incorporando a importância de notificação destes incidentes além de direito e segurança do paciente $\mathrm{e}$ soluções legais para os eventos adversos e dos problemas jurídicos resultantes destes.

A segunda parte da obra aborda a avaliação do risco em organizações de saúde e seus capítulos versam sobre: infecções associadas aos cuidados de saúde, onde é demonstrado que assistência limpa é assistência mais segura levando a avaliação dos riscos, prevenção da transmissão e empoderamento sobre a importância da criação dos programas de controle de infecções nas unidades; erros relacionados aos medicamentos nos demonstra a todas as particularidades que são inerentes a essa temática que vão desde a prescrição, passando pela transcrição, distribuição, preparação até a administração e que existe a necessidade de uma série de padronizações, fluxos e rotinas para minimizar a chance dos eventos adversos envolvendo os medicamentos.

A questão da cirurgia segura remete aos processos de trabalho que devem ser instituídos, otimizando a comunicação, e para isso, foi criada a lista de verificação de segurança na cirurgia que contempla tópicos que envolvem a entrada, o momento da cirurgia e a saída do paciente da sala de cirurgia, itens que minimizam a ocorrência de lesões com danos para os pacientes. Refletir sobre a segurança do paciente e o diagnóstico destaca a importância dos protocolos e diretrizes institucionais como ferramentas para minimizar o erro diagnóstico, além dos erros relacionados ao laboratório que podem ser encontrados nas três fases do processo laboratorial (pré-analítico, analítico e pós-analítico). O livro expõe como podemos prevenir acontecimentos adversos com padronização, treinamento, controle de qualidade, instituição de indicadores de segurança.

Encontra-se ainda a gestão do risco de quedas, úlceras por pressão e de incidentes relacionados com transfusão de sangue e hemoderivados informando como agir para reconhecer fatores intrínsecos e extrínsecos que podem 
provocar quedas e úlceras por pressão e os passos que devem ser seguidos com a finalidade de evitar os incidentes durante as hemotransfusões.

A abordagem da segurança do paciente na Atenção Primária traz os principais tipos de eventos que podem ocorrer neste nível do cuidado como: erro diagnóstico e no tratamento e organização do serviço. Expõe que a superlotação dos serviços de emergência apresenta-se como uma forma de vulnerabilidade à segurança do paciente $\mathrm{e}$ que o acolhimento e classificação de risco podem ser utilizados para diminuir o risco de eventos adversos, com uma gestão de risco não clinico levando-se em consideração as normas vigentes e o monitoramento dos diversos setores $\mathrm{e}$ equipamentos das unidades hospitalares. Destaca a maternidade segura revelando seus problemas, papel e estratégias com a finalidade de garantir a qualidade nos serviços obstétricos.

Tudo isto revela uma obra ampla sobre o tema, com olhar multidisciplinar e leitura acessível que atende aos anseios daqueles que buscam se aprofundar na temática de segurança do paciente. Apresenta-se com abordagem limitada à Atenção Primária considerando-se a sua importância na promoção da mudança da cultura sobre o tema segurança do cuidado e cuidador.

\section{Referência}

1. Sousa P, Mendes W. Segurança do Paciente Conhecendo os Riscos nas Organizações de Saúde, Rio de Janeiro: Fiocruz: 2016. 